\title{
INSURGÊNCIAS NAS TRAJETÓRIAS EM DIÁSPORA DE UNIVERSITÁRIAS HAITIANAS EM BELO HORIZONTE, BRASIL
}

\section{Camila Rodrigues Francisco ${ }^{1}$ \\ Claudia Mayorga²}

Resumo: A palavra insurgência, em seu significado dicionarizado, evoca uma organização que vai contra um movimento hegemônico; é utilizada sobretudo em contextos de rebelião contra um sistema social e político. Este artigo objetiva pensar como o deslocamento territorial de mulheres haitianas, motivado por questões estudantis, aponta para insurgências sobre a forma como as coisas são em um momento histórico, político e econômico, e em vários níveis. Confluímos com uma proposta teórica de insurgência como uma transgressão de um estado de coisas que se propõe instituído, articulando-a com os relatos das duas universitárias haitianas interlocutoras da pesquisa de mestrado aqui mencionada. Palavras-chave: Diáspora haitiana; estudantes haitianas; migrações estudantis.

\begin{abstract}
In the dictionary, the word insurgence means some kind of organization that goes against a hegemonic movement and it is used mainly in contexts of rebellion against a social and political system. With this article, we show that the territorial displacement of Haitian women indicates an insurgence in the way things work at a given political, historical and economic time. We propose a theoretical framework wherein insurgency is a transgression of a currently instituted state of things, and apply it to the reports provided by the final project of a master's degree from two Haitian women who are university students.
\end{abstract}

Keywords: Haitian diaspora; university and diaspora; gender and diaspora; Haitian students.

\section{Introdução}

A palavra insurgência, em seu significado dicionarizado, evoca uma organização que vai contra um movimento hegemônico estabelecido. É utilizada

\footnotetext{
1 Mestre em Psicologia Social pela Universidade Federal de Minas Gerais, Minas Gerais, Brasil. E-mail: cfmilarodrigues@gmail.com. Orcid: 0000-0002-9867-9095

2 Doutora em Psicologia Social pela Universidad Complutense de Madrid, Espanha. Professora do Departamento de Psicologia da Universidade Federal de Minas Gerais, Brasil. E-mail: claudiamayorga@ufmg.br. Orcid: 0000-0003-1728-0726
} 
sobretudo em contextos de revolta, rebelião contra um sistema político, social elou de crenças fortemente construído.

É um termo apresentado para descrever processos históricos que se apresentam como uma transgressão ao poder vigente. Em artigo que discute o efeito das atividades insurgentes no período da ditadura civil- militar no Brasil no campo da Psicologia, Domênico Hur e Fernando Lacerda Júnior (2017, p. 29) localizam, no Brasil, as seguintes lutas insurgentes contra o Estado:

os movimentos de resistência escrava no período colonial, como a Guerra dos Palmares, movimentos independentistas no período imperial, como a Inconfidência Mineira de Tiradentes, movimentos insurrecionais religiosos no período imperial e republicano, movimentos pela terra e dos trabalhadores no período republicano, entre muitos outros.

Trata-se inclusive de um termo em disputa, ora apropriado em seu sentido estrito de movimento político de transformação - que busca se tornar hegemônico - por uma minoria, ora como uma tipificação criminosa como ocorre no campo jurídico brasileiro ${ }^{3}$.

Podemos encontrar debates teóricos de apropriação do termo nas ciências humanas e sociais ${ }^{4}$, sobretudo a partir da obra do antropólogo estadunidense James Holston, da qual parte o conceito de cidadanias insurgentes para pensar sobre tais formações dentro da democracia brasileira. Para fins deste artigo, confluímos, portanto, com a perspectiva do termo insurgência como uma dissidência ou transgressão de um estado de coisas que se propõe hegemônico, instituído. $\bigcirc$ sociólogo francês René Lourau discute a dialética do instituído e instituinte a partir dos paradigmas teóricos de sua obra sobre a Análise Institucional, citado no trabalho da pesquisadora brasileira Roberta Romagnoli (2014, p. 47):

Ou seja, a instituição se encontra em algum lugar entre o revolucionário do instituinte e o conservador do instituído; contra as forças instituintes e sua rebeldia, a institucionalização busca formas mais estáveis, rígidas e duradouras; e contra o instituído e

3 A Lei nº 1.802, de 5 de janeiro de 1953, também chamada de Lei da Segurança Nacional, tipifica, em seu artigo terceiro, como crime, a insurreição armada contra o estado (BRASIL, 1953).

4 Discussão acerca dos espaços públicos urbanos como contextos insurgentes de cidadania (REGINENSI; MENEZES, 2009); reflexão sobre a própria cidadania brasileira a partir do conceito de Houston (SILVA, 2017); debate em torno de como a aliança eventual entre a esquerda e o Estado tem produzido, não necessariamente por intenção, um "apaziguamento" das forças insurgentes ao longo da história, processo que envolve também uma captura das subjetividades (LACAZ, 2018); e ainda o espaço público em disputa a partir das performances de cidadania com o movimento de Slam Resistência em São Paulo (FREITAS, 2020). 
sua imutabilidade busca mudanças inovadoras nas formas até então utilizadas. Deve ficar claro que esta separação é apenas didática, uma vez que, para o referido autor, a instituição é um moto-contínuo, processo sustentado por essas forças dialéticas.

Pretendemos demonstrar que o deslocamento territorial das mulheres haitianas interlocutoras da pesquisa mencionada aponta para uma política de insurgência do status quo, da forma como as coisas são em um momento histórico, político e econômico, e em vários níveis, a saber, no nível das dinâmicas familiares, de gênero, raça, território e outras dinâmicas relacionais. Em outras palavras, lançamos as seguintes reflexões: como as insurgências aparecem em trajetórias como as das interlocutoras aqui mencionadas, ou ainda, como as trajetórias diaspóricas de estudantes haitianas apontam para insurgências de vários tipos?

Os relatos de tais interlocutoras estão na pesquisa de Mestrado em Psicologia Social intitulada Trajetórias em diáspora: a experiência de universitárias haitianas de Belo Horizonte (FRANCISCO, 2019). Por meio de metodologia qualitativa, conjugamos observação participante, entrevistas e pesquisa bibliográfica, que ocorreram por meio da participação em eventos da comunidade acadêmica internacional na cidade de Belo Horizonte, conversas informais com quatorze estudantes universitárias estrangeiras negras de países africanos (Benin, Cabo Verde, Camarões, República Democrática do Congo, Moçambique) e do Haiti, e entrevistas semiestruturadas com as duas estudantes haitianas escolhidas como interlocutoras principais da pesquisa, Michou e Judie. Todo o processo da pesquisa foi registrado em diário de campo.

A construção do campo-tema (SPINK, 2003) da pesquisa partiu da observação de uma seletividade no tratamento das pessoas estrangeiras no Brasil. Analisar essa seletividade de tratamento dentro da universidade foi a justificativa inicial, norteada pelo questionamento acerca dos aspectos que produzem essa diferença. Fazer essa reflexão a partir do debate da diáspora negra, da migração e do gênero se apresentou como muito potente para o que se pretendeu abordar.

Dessa maneira, tomaremos como premissa teórica um pensamento em torno das rotas e raízes da diáspora negra/africana que parte dos pesquisadores estadunidenses Edmund Gordon e Mark Anderson (1999). Confluímos com a perspectiva de que há uma diáspora iniciada pelo processo colonizatório desde o território africano para as Américas, e sendo assim, há uma conexão pela origem - que tinha uma demarcação territorial, mas também uma imensa complexidade de outros fatores (culturais, sociais, políticos, econômicos, 
religiosos etc.) - que tem sido recriada e reinventada. Escolhemos o Haiti como interlocutor entendendo que populações em diáspora em seus novos territórios configuram novas diásporas de formações muito distintas, e por isso falamos em uma diáspora africana no século $X X$, em uma diáspora haitiana, e nos possibilitaria falar também em uma diáspora brasileira.

Se a migração diz respeito a um deslocamento de um local para o outro (com motivações específicas, com um projeto individual ou coletivo e que produz a condição migrante), toda diáspora diz de algum tipo de migração. Por outro lado, não são todos os deslocamentos que interpelam os territórios acerca de suas identidades elou produzem reconfigurações identitárias em si mesmas (APPADURAI, 1997; HALL, 2011; CLIFFORD, 2011; GILROY, 2001). É nesse sentido que nem todas as migrações se configuram em diásporas (FRANCISCO, 2019).

\section{A Diáspora e a diáspora estudantil na história do Haiti}

Para iniciar este tópico, localizaremos a diáspora haitiana tomando como base a própria trajetória histórica do país. A diáspora estudantil integra esse cenário e deve ser analisada em suas especificidades.

Segundo o intelectual haitiano Joseph Handerson (2015), identifica-se que os primeiros usos do termo "diáspora haitiana" remontam aos anos de 1980, para designar a experiência de haitianos e haitianas que se encontravam nos Estados Unidos da América (EUA) como refugiados políticos da ditadura duvalierista ${ }^{5}$. Segundo o autor, os padres católicos foram os protagonistas na mobilização do termo em prol de uma organização política de reivindicação dos direitos nos EUA bem como de denúncia ao regime ditatorial haitiano. A partir de 1986, com o retorno dos expatriados ao país, o termo se popularizou e a partir de 1990 o uso do termo "dyaspora" se generalizou e começou a fazer parte do vocabulário créole, língua oficial haitiana junto com o francês.

$\bigcirc$ autor etnografa o termo a partir dos relatos de haitianos e haitianas que vivem no exterior, demonstrando que o termo se refere às pessoas - que saem por um tempo, voltam para visitar mas não voltam a residir - e se torna também um adjetivo de tudo o que é produzido por tais pessoas, como as músicas diáspora, roupas diáspora, as casas que são construídas com ajuda ou

5 Segundo Elizeu Chaves Júnior (2008), em 1937 se iniciou um período ditatorial no Haiti por meio da autoproclamação de François Duvalier como presidente vitalício, gestão que foi continuada por seu filho, Jean Claude Duvalier, entre 1971 e 1986. Para garantir a soberania por meio da violência e autoritarismo, criou-se um exército próprio, os tonton macoutes, e o governo foi instituído com o apoio da hierarquia eclesiástica, a tecnocracia Estatal e os setores centrais da burguesia. 
pelos próprios residentes no exterior - casas diáspora - a moeda diáspora ou lajan diáspora, que diz respeito ao euro etc. (HANDERSON, 2015).

O Haiti é um país marcado historicamente pelos deslocamentos ao exterior e isto impacta diretamente em sua realidade atual. Ainda segundo o autor, em 2007, as remessas enviadas por pessoas em diáspora para familiares no país chegaram a representar $24 \%$ do Produto Interno Bruto (PIB) anual, dados que não contemplam os envios informais (HANDERSON, 2015). Podemos sinalizar três fluxos diaspóricos que marcam e são marcados pela história do país: o período que data da pré-independência até sua proclamação, no século XVIII; os efeitos do pós-independência, que emergem no século XIX; e os desdobramentos do século $X X$, que vão deixando rastros no século XXI.

Ao mobilizar leituras acerca do processo histórico no Haiti e sua situação econômica e política atual, parece não ser novidade dizer que há um conflito de interesses políticos que colocou e mantém o Haiti como um país subalterno desde a sua independência (SEGUY, 2014; QUEIROZ, 2017). Podemos apontar alguns fatores que se combinaram para produzir esta subalternidade:

a) a pesada indenização cobrada pela França para reconhecer a independência do país depois de ter visto seus colonos serem mortos ou expulsos da ilha; b) o forte embate entre mulatos e negros no período de constituição nacional; c) a dificuldade de se instaurar e reconhecer uma classe dirigente que se impusesse legitimamente, e que defendesse os interesses nacionais; d) o legado escravocrata, posto que, mesmo após a independência, conquistada graças ao levante dos escravos, as massas recém-libertas não tiveram acesso à posse dos meios de produção, particularmente a terra, ou ao trabalho assalariado; e) a herança monocultora que se tornou cega à necessidade de diversificar a economia para que o mercado interno fosse sustentável. Diante deste quadro, é plausível que o surgimento e intensificação dos fluxos migratórios internacionais de haitianos estejam diretamente relacionados com as sucessivas crises políticas e com as alternativas de saída da pobreza. (BAPTISTE; VIEIRA apud MAGALHÃES, 2015, p. 70).

Ou seja, parece não ser novidade para a literatura também que o deslocamento territorial ao exterior esteja diretamente relacionado a este contexto de espoliação (MAGALHÃES, 2017; SEGUY, 2014; CHAVES JÚNIOR, 2008). O ano de 2010 é marcadamente terrível para o país, conforme aponta o representante brasileiro de assuntos internacionais no Haiti, Ricardo Seitenfus (2016): além do terremoto em 
janeiro que causou a morte de mais de 230 mil pessoas, houve também a cólera que chegou pelas tropas do Nepal da Missão de Estabilização das Nações Unidas no Haiti (Minustah) e se espalhou pelo país, deixando cerca de 8 mil mortos e 800 mil infectados; e a tentativa da Organização das Nações Unidas (ONU), da Organização dos Estados Americanos (OEA) e da Comunidade Internacional de impor um candidato contrário à vontade popular. Estima-se que 350 mil pessoas saíram para o exterior naquele ano, assim como outras se deslocaram ao meio rural (HANDERSON, 2017).

Portanto, a leitura que compartilhamos com tais autores sobre a sociedade haitiana envolve compreender que a situação precária do país se agravou em 2010, mas já estava ocorrendo historicamente desde as tentativas pioneiras para se libertar dos grilhões da ocupação colonial, já que o Haiti é, nas Américas, o "primeiro estado independente construído por ex-escravos e negros libertos das Américas" (QUEIROZ, 2017, p. 67).

Existe um fenômeno migratório amplo entre Haiti e Brasil relacionado às políticas econômicas internacionais, à modernidade e à colonização ${ }^{6}$. Por ora, aponto que entender o processo histórico apresentado brevemente aqui é importante para percebermos que a diáspora haitiana não tem a ver somente com uma questão econômica e que tampouco está relacionada apenas à inserção no mercado de trabalho.

Os primeiros deslocamentos motivados pela questão estudantil da antiga ilha de São Domingos datam do pré-independência, já que não havia escolas no Haiti durante o período colonial; os filhos de mulatos e brancos que eram enviados para a França (GRONDIN, 1985). A ida destes jovens vinculados à elite econômica do país à então colônia - França e mais tarde, a outros países de relativa potência econômica e intelectual Estados Unidos e Canadá - aparece como característica recorrente. Nesse sentido, o fenômeno tem se modificado, pois parecia estar relacionado apenas às classes superiores.

No estudo da psicóloga Marcela Gomes acerca dos impactos subjetivos da imigração haitiana no Brasil, encontramos que há distinções importantes

6 Os fluxos migratórios do Haiti para o Brasil se estreitaram a partir dos anos 2000 com a criação da Minustah por meio de uma Resolução do Conselho de Segurança da ONU em 2004, e se intensificaram a partir de 2010. Ainda que o objetivo da missão fosse assegurar a segurança do país, tanto a criação quanto sua ocupação revelavam ambiguidades políticas bastante complexas (SEGUY, 2014; MAGALHẨES, 2015; SEITENFUS, 2016; HANDERSON, 2017). Uma delas era de que foi dispendido um grande contingente militar para lidar com um problema que deveria e poderia ser coordenado pela polícia local. Outra está presente no discurso de paz aliado à produção de outras violências: o jornalista brasileiro lgor Patrick (2017) traz relatos de mulheres haitianas que denunciaram estupros de oficiais vinculados à Minustah, articulando com as estimativas oficiais que apontam para 114 denúncias de estupro envolvendo civis, policiais e militares entre 2010 e 2017. 
nas experiências de estudantes e trabalhadores migrantes. Os últimos estariam sujeitos a maiores vulnerabilidades psicossociais e um dos maiores motivos apontados foi a busca por melhores condições de vida, em termos de economia, que tornaria este deslocamento uma necessidade; os estudantes haveriam se deslocado por questões outras como estudos, viagem, interesse pela cultura, sendo um deslocamento voluntário (GOMES, 2017).

A autora chama atenção, porém, para o fato de que tal diferenciação não deve ser vista como uma dicotomia rígida já que existem motivações e explicações mais complexas em ambos os casos. $O$ relatório feito pelo Observatório das Migrações (OBMigra) a partir dos dados do Ministério da Economia entre 2010 e 2018 mostra que, no que se refere ao nível de instrução da migração de trabalhadores migrantes no Brasil, predomina-se o ensino médio completo, sendo que $54,8 \%$ dos trabalhadores haitianos e haitianas possuem escolaridade inferior ao nível médio e 1,8\% possuem nível superior (SIMÕES et al., 2019). Nesse sentido, é importante ressaltar ainda que o Brasil é apresentado como um país "atraente" pelos chamados coiotes - agenciadores ilegais de viagem em países como o Haiti, que prometem empregabilidade fácil e salários muito altos (FERNANDES; FARIA, 2017).

Outra reflexão que nos parece pertinente aqui está relacionada ao ensino superior público brasileiro. A filósofa brasileira Marilena Chaú (2003) aponta que a universidade pública se coloca como um espaço de autonomia e legitimidade perante outras instituições sociais, como herança da Revolução Francesa em torno do público e do laico e dos impactos das revoluções sociais do século XX com relação aos direitos dos cidadãos e cidadãs à educação e cultura. Nos últimos anos, precisamente, a partir dos anos de 1990, quando a inclusão das políticas de ações afirmativas começa a se fortalecer, a universidade brasileira pública tem se modificado. Podemos identificar também outras iniciativas, como as ações de extensão - que aproximam a universidade da comunidade, reduzindo as distâncias entre estes dois espaços que foram historicamente construídas -, as políticas de democratização do acesso e permanência e, por último, as próprias políticas de internacionalização que agregam estudantes de várias partes do globo.

Um dos acordos diz respeito ao Programa de Estudantes-Convênio de Graduação (PEC-G), um dos tratados que o Brasil assinou com países em desenvolvimento por meio do qual recebe estudantes para realizarem estudos de Graduação nas instituições de ensino superior brasileiras. Segundo a pesquisadora brasileira Joana Amaral (2013), ele foi criado em um contexto 
de grande fluxo de estudantes internacionais no Brasil, mas só em 1974 é que o programa deixou de ser restrito aos estudantes latino-americanos. Já foi administrado pela Capes, mas atualmente sua gestão é feita pela instituição que o criou, o Ministério de Relações Exteriores, junto ao governo dos países concordantes. $\bigcirc$ acordo conta com 59 países participantes, da África, das Américas e da Ásia, sendo a África o continente que mais enviou estudantes desde o início do convênio. Ambas as interlocutoras dessa pesquisa chegaram ao Brasil por meio do PEC-G.

\section{Diáspora, gênero e raça}

Ao decidir mergulhar nas inquietações acerca do gênero, território e nacionalidade, partimos de uma questão norteadora: o racismo na sociedade brasileira. Ao nos perguntarmos sobre a seletividade do tratamento aos diversos estrangeiros e estrangeiras em nosso país, entendemos que a questão racial deveria ser uma das respostas ou um dos critérios.

$\bigcirc$ antropólogo estadunidense James Clifford (2011) aponta o cuidado que devemos ter ao diasporizar ou internacionalizar as minorias, desviando-se das desigualdades estruturais, como a raça, a classe e - podemos agregar nesta análise - o gênero. Pensando a partir da cultura, o autor afirma que as teorias sobre a diáspora precisam dar conta dos entrecruzamentos estruturais que podem ficar esquecidos nas análises que focam no "multinacionalismo" como o problema central.

Pensar em termos das desigualdades de gênero nos processos de deslocamento territorial implica analisar que, ainda que seja um fenômeno majoritariamente masculino, não significa que as mulheres não fazem parte do processo ou que devamos reduzi-las a acompanhantes. Nesse sentido, outra virada proposta na articulação de teorias feministas com o debate da migração é que ela pode ser pensada, planejada e gestada em um lugar de autonomia para as mulheres (MAYORGA, 2011; FERREIRA, 2017). Uma das questões que dai emergem é a necessidade de uma mudança nos aportes teóricos e metodológicos que tendem a ver as mulheres como agentes secundárias, vistas como "acompanhantes, dependentes ou simplesmente invisiveis nos fenômenos analisados" (PERES, 2017, p. 240).

A chave para pensarmos as questões de gênero e raça nestes termos estaria na seguinte reflexão: se os sujeitos e sujeitas da diáspora são versões distintas da experiência intercultural, moderna e transnacional, ela não pode ser o único 
quadro de nossas análises, pois tais "identidades modernas" estão atravessadas por raça, sexo, gênero, classe, cultura etc. (CLIFFORD, 2011, p. 109). Com o também pesquisador estadunidense Edmund Gordon (2006), concordamos que: partindo deste pressuposto, raça não é adequadamente entendida ou vivida abstraindo-se interarticulação e constituição mútuas de eixos como gênero, classe e sexualidade (ou pelo menos estes).

Em pesquisa na área de psicologia social, Claudia Mayorga e Rubens Nascimento (2009) analisa os efeitos patriarcais e coloniais que a ausência de uma perspectiva crítica de gênero e das relações de poder pode ter nos estudos sobre migração e na caracterização dos problemas sociais diversos, como, por exemplo, no que está delimitado como tráfico de mulheres.

A pesquisadora brasileira Marilise Reis (2011, p. 8) aponta ainda que ao articular tais categorias na experiência da diáspora, temos "uma nova episteme em emergência"7, que diz respeito à ressignificação e à recriação das narrativas de emancipação, redenção e democratização que não se enfocam no Ocidente, e se coloca como uma contracultura transnacional do "Atlântico Negro". James Clifford (2011) chama atenção para uma política ambivalente da diáspora que a experiência das mulheres revela.

A ambivalência está em perceber que, ao mesmo tempo em que conserva os vínculos com as redes de parentesco - e por conseguinte, com as tradições que por vezes mantêm estruturas patriarcais e sexistas -, a própria experiência de diáspora coloca estas mulheres em outros papéis, ou, como aponta o autor, em novos espaços políticos. Ao articular estas duas comunidades, a de origem e a de destino, temos que: "As experiências vividas pelas mulheres diaspóricas implicam, assim, a dolorosa dificuldade de mediar entre mundos discrepantes. A comunidade pode ser o lugar tanto do apoio quanto da opressão" (CLIFFORD, 2011, p. 100, tradução nossa).

\section{Insurgências nas trajetórias de Judie e Michou}

Como apresentado anteriormente, esta pesquisa envolve centralmente duas interlocutoras, que são universitárias haitianas residentes na cidade de Belo Horizonte. Nascida em Porto Príncipe, capital federal do Haiti e com 27 anos, Michou cursava o $8^{\circ}$ semestre da Graduação

\footnotetext{
7 Apontamos ainda que, na tentativa de articular a dimensão da diáspora africana com a especificidade da experiência das mulheres negras, algumas autoras cunharam o termo feminismo negro diaspórico (ou feminismo afrodiaspórico) para designar esta articulação entre a noção de diáspora africana com a questão do gênero (SANTOS, 2000; FIGUEROA; HURTADO, 2014).
} 
em uma universidade federal. Chegou no Brasil no ano de 2014. Judie, 23 anos, nasceu também em Porto Príncipe e cursava o $2^{\circ}$ semestre em uma universidade privada. As duas eram amigas (foi Michou quem me conectou a Judie), moravam em bairros diferentes (mais próximos de suas respectivas faculdades) e não tinham relação nenhuma antes da vinda ao Brasil. Chegam em momentos diferentes, tendo suas escolhas pelo deslocamento também motivadas por razões diferentes.

Antes de ser a primeira estudante haitiana do seu curso, Judie foi a filha que saiu da casa de seus pais, com 17 anos, para morar numa casa mais próxima ao centro para se dedicar ainda mais aos estudos, mas também por uma motivação muito pessoal, que ela diz em "eu queria a minha liberdade". Terminou o ensino médio e depois de um ano trabalhando fez o processo para estudar fora. Essa experiência envolveu trabalhar em escolas de educação infantil, mas também em uma ONG cujo trabalho é similar ao Médicos sem Fronteiras. Trabalhou também com o ministério da saúde pública. "Todo mundo falava mal de mim", diz ela, sobre ela sair tão cedo de casa, sendo mulher e solteira. Teve que enfrentar os pais para conseguir fazer isso. Se lembra que quando pequena, sua saída para fugir dos afazeres domésticos que a mãe sempre a interpelava era pegar um livro, que nem sempre ela lia de verdade. Quando saiu de casa o comentário era: "deixaram ela ler livros e deu nisso". Quando ela contou sua ideia de sair do país, diz que

[...] foi estranho para os meus pais, eles falam... que morar num país sozinha, não é uma boa ideia. E... mas, eu tenho, tipo, eu tinha ideia de estudar fora da minha terra, $e$ mesmo, na primeira vez, eles ficaram... bem chateados comigo, mas depois eles concordaram. (informação verbal) ${ }^{8}$.

Hoje ela afirma que sua família dá muito apoio à sua escolha de seguir investindo em formação acadêmica, principalmente porque agora eles confiam e entendem que de fato é esse o projeto que ela tinha em mente quando saiu de casa pela primeira vez (pois havia um medo reiterado de que ela fosse "se perder", no sentido de se envolver com algum homem antes de se formar ou mesmo de casar).

"Sempre foi meu sonho estudar fora" (informação verbal)", diz Michou, porque queria conhecer o mundo. Antes de vir ao Brasil, começou outra

8 Informações fornecidas por Judie em entrevistas, em Belo Horizonte, em 5 de setembro de 2018 e 8 de dezembro de 2018.

9 Informação fornecida por Michou em entrevista, em Belo Horizonte, em 25 de agosto de 2017. 
Graduação no Haiti. Sobre a decisão de se mudar para outro país para estudar, a mãe teve aquele receio esperado, mas concordou. Ela só contou para os pais depois que houve a confirmação da vinda (pois já havia tentado outras opções que não resultaram).

A intelectual chicana Glória Anzaldúa (2005) aponta que, em algumas situações, as mulheres que ousam questionar alguns sistemas de ocupação do espaço público se sentem incompreendidas pelos seus, ou seja, pelas pessoas de seu próprio grupo. Parece interessante pensar sobre as negociações que precisam ser feitas para tornar esta trajetória de se dedicar aos estudos uma trajetória possivel enquanto mulher. Ainda de acordo com o pesquisador brasileiro Rubens Ferreira (2017, p. 121):

\begin{abstract}
Ademais, para essas jovens mulheres, o projeto de estudar em outro país gera expectativas quanto à vida fora do jugo familiar, portanto, longe da casa, da vizinhança e da sociedade na qual os hábitos e comportamentos são vigiados e controlados na esfera do que se tem como um espaço social pré-definido para ser mulher, e do que se espera delas em relação aos papéis de gênero.
\end{abstract}

Essa trajetória de busca por autonomia tida como atípica para as mulheres também parece estar presente no relato anterior de Judie e na perspectiva de Michou quando esta afirma que "as pessoas pensam que as mulheres são fracas" (informação verbal) ${ }^{10}$. Na pesquisa de Handerson e Joseph (2015) sobre mulheres migrantes haitianas na França e no Brasil, demonstrou-se que também elas se deslocam para buscar uma ascensão econômica para elas e suas famílias, deixando marido e filhos no país de origem, e atravessando dificuldades e encarando as desigualdades pelo racismo, o machismo e a xenofobia aos quais estão expostas (HANDERSON; JOSEPH, 2015).

Articulando a ideia de agência e das negociações possíveis, passaremos agora a uma compilação de relatos de Judie e Michou ao longo da pesquisa, acerca do que elas entendem sobre o ser mulher no Haiti.

Quando falamos sobre o ser mulher no Haiti, Judie considera que "há uma revolução das mulheres para elas poderem estudar e ocupar o espaço público". Diz ainda que, quando estava na escola, se lembra de haver incentivo para que as meninas crescessem e continuassem a estudar; inclusive ela mesma ganhou uma eleição para líder de sala, concorrendo com um menino. Quando falamos sobre o fato de serem homens os que saem em

10 Informação fornecida por Michou em entrevista, em Belo Horizonte, em 8 de dezembro de 2018. 
sua grande maioria do país para estudar, ela discorda, dizem que talvez em sua cidade (capital do país) não seja assim, pois

\begin{abstract}
Cada cidade tem uma forma de ver as mulheres. As mulheres em alguns lugares nem estudam. O final da vida delas é o casamento e isso tem a ver com a religião e os costumes da familia. Se você vai se casar em algumas igrejas, e não é virgem, seu véu fica na parte de trás da cabeça, e não pode cobrir o rosto [ou seja, todos podem ver que você não é pura]. Nas igrejas evangélicas a pessoa que não é virgem e se casa, ela é mais isolada.
\end{abstract}

A mãe de Judie, por exemplo, só estudou até o $6^{\circ}$ ano. Já os homens "saem de casa para trabalhar e as mulheres ficam em casa pra cuidar dos filhos. Antigamente, se você tinha seis filhos na casa e só um homem, só ele ia à escola porque ele poderia ser engenheiro, médico, e até presidente". Sobre o trabalho, ela conta que as mulheres limpam a casa e cuidam dos filhos e, nas classes mais baixas, ainda saem para vender coisas na cidade. Conta ainda uma outra forma de prescrição que aparecia quando as meninas ou mulheres queriam estudar: "se você vai pra escola, vai aprender a escrever para homens!". Para ela, uma de suas irmãs vive nesta lógica do ser criada para o casamento, já ela: "Eu acho que sou uma mulher de sorte. Eu quero ser a mulher que eu estou procurando. Eu sou a pessoa mais inteligente da minha familia. Às vezes as mulheres pensam que as mulheres são fracas" (informação verbal)"11.

Michou vê que a mulher num contexto geral: "é um pilar da sociedade; ela tem a responsabilidade de prover, de manter e de cuidar". Percebe que "muitas mulheres no Haiti são oprimidas ao ponto de não se sentirem à vontade nem de falar. Isso tem a ver com a história, e isso é mais antigo", mas, segundo ela, isso tem se modificado. Aponta que o feminismo é um movimento de elite, ou seja, aparece de maneira mais marcada em mulheres de classe social elevada. Quando falamos sobre a migração para estudar ser um fenômeno ainda majoritariamente masculino, ela percebe que "a sociedade não exige tanto do homem"; essa pode ser uma das razões que faz com que saiam mais homens que mulheres do país, porque os pais têm medo de deixar as filhas saírem, porque veem a mulher como um ser vulnerável (informação verbal) ${ }^{12}$.

No relatório Gender issues in Porto Príncipe (Questões de gênero em Porto Príncipe), produzido a partir dos dados encontrados pela ONG brasileira Viva Rio durante anos de trabalho no Haiti, apresentam-se estimativas de

11 Informação fornecida por Judie em entrevista, em Belo Horizonte, em 8 de dezembro de 2018.

12 Informação fornecida por Michou em entrevista, em Belo Horizonte, em 8 de dezembro de 2018. 
que mais de $60 \%$ das mulheres que vivem na área metropolitana de Porto Príncipe são chefes-de-familia, o que significa que cuidam de seus filhos e suas casas sozinhas (BRAUM; DALMASO; NEIBURG, 2014).

Por outro lado, elas também são envolvidas diretamente com a economia da região, pois mais de $70 \%$ das mulheres estão no comércio. Somando estes dois fatores, as mulheres e as crianças são as maiores vítimas das condições de precariedade que o país vive: quando haitianos e haitianas foram perguntados sobre questões de gênero no âmbito da pesquisa de tais autores, ambos mencionam a violência conjugal, doméstica ou interpessoal, em que pese ainda o fato de que as violências - sobretudo sexuais - perpetradas contra as mulheres se agravam em momentos políticos de conflito armado (MATUELLA, 2017), como já apontamos no capítulo anterior sobre a Minustah no Haiti.

Judie mencionou durante uma das entrevistas as mulheres em cargos presidenciáveis. Ertha Pascal-Trouillot governou o país em 1990 como resposta ao golpe militar, sendo ela a presidente da Corte Suprema à época. Esteve por menos de um ano no governo, convocando eleições presidenciais em dezembro do mesmo ano, eleição que venceu Jean Bertrand-Aristide. No ano de 2010, em que venceu Michel Martelly, cantor famoso no país como mencionado por ela, concorria também outra mulheres ao cargo presidenciável: Mirlande Manigat, que foi primeira dama de Leslie Manigat, presidente do país em 1988, que tinha uma pequena experiência política desta época e era formada em Ciência Política (ELEIÇÕES..., 2010).

Como apontado por Judie e Michou, as dinâmicas e as relações de gênero no país têm se modificado ao longo do tempo, como revelado também em suas próprias trajetórias em alguma medida pioneiras em seus contextos locais, e isto está diretamente relacionado à própria organização política das mulheres.

Retomando o lugar da universidade neste processo, no relatório mencionado anteriormente, os autores revelam que o capital educacional é identificado, sobretudo, pelas pessoas de classes mais baixas, como um princípio poderoso de diferenciação no mercado de trabalho, seja interno ao país, seja o externo ao qual haitianos e haitianas têm acesso (BRAUM; DALMASO; NEIBURG, 2014). Na pesquisa de conclusão de curso do haitiano Jude Civil, as mulheres haitianas entrevistadas falam sobre a relação entre a educação e a busca por autonomia e emancipação da mulher, pensando inclusive em um retorno a seu país para fomentar tais discussões 
que elas entendem como necessárias. Isso ocorre justamente por reconhecer que, no Brasil, a desigualdade de gênero tem semelhanças e afastamentos com o Haiti: ainda que os direitos das mulheres sejam mais valorizados aqui, na opinião delas, porém, as condições de violência às quais estão expostas parecem as mesmas (CIVIL, 2018).

Retomando a experiência relatada pelas estudantes, no que se refere à chegada delas no Brasil, na segunda vez em que conversamos, Michou me contou que fez "um barraco na Polícia Federal (PF)", pois demoraram para a atender, deram preferência a um dinamarquês com vários esforços e mímicas para atendê-lo e entendê-lo, enquanto ela levava o papel todo escrito em português com o que ela precisava exatamente; quando finalmente chegou na sua vez, informaram que o horário já havia encerrado naquele dia. Ela me diz que recebeu uma multa por estar no país três dias sem a autorização, e por isso fez o "barraco", pois era injusto pagar esse valor já que não foi culpa sua o atraso, mas do tratamento péssimo dado a ela. Comenta que falou de acionar um setor responsável por estas reclamações, para que as devidas providências fossem tomadas, e então a multa foi abonada e seu problema resolvido. Diz que isso "sempre acontece" (o tratamento diferente na PF) (informação verbal) $)^{13}$ e que consegue perceber explicitamente que tem a ver com ser preto ou ser branco, europeu etc.

Eu nunca não vou esquecer desse dia tão... pesado pra mim. Eu cheguei aqui às $2 \mathrm{~h}$ da madrugada. Eu tinha um amigo que foi ao aeroporto para me buscar, mas quando eu cheguei lá em São Paulo, às 20/21h foi um pesadelo, porque é bem grande, bem estranho, eu não sabia falar nada em português, nada, nem bom dia, mas mesmo assim eu consegui. Porque a minha língua, que eu falo, é francês, mas eu não achei nenhuma pessoa que fala francês, mas com o gesto eu consegui, porque eu mostrei algumas passagens - a minha passagem -, e as pessoas me indicaram onde tinha que ir pra pegar o avião para vir aqui para Belo Horizonte. [...] Eu, quando cheguei, fiquei três dias na casa de um amigo. E depois eu mudei para uma casa, para conviver com as africanas (Judie) ${ }^{14}$.

Judie disse não ter tido nenhum problema na PF.

Desde a chegada, estas estudantes se veem expostas às situações violentas; com o tempo, o quebra-cabeça das razões pelas quais tais situações acontecem começa a se encaixar. Isto é, se não se nomeava antes tais

13 Informação fornecida por Michou em entrevista, em Belo Horizonte, em 18 de janeiro de 2018.

14 Informação fornecida por Judie em entrevista, em Belo Horizonte, em 5 de setembro de 2018. 
experiências como algo motivado pela questão racial, na experiência brasileira, isso se torna evidente. Tais relatos nos remetem às reflexões sobre o funcionamento da democracia racial e do racismo na sociedade brasileira: a seletividade existe, mas evita-se e/ou silencia-se quem fale sobre ela.

A intelectual amefricana Lélia Gonzalez (1982) aponta que o maior efeito do mito da democracia racial é a negação de que somos racistas, sob o discurso de um paraíso racial que se materializou na miscigenação. Dessa forma, se nega e silencia a realidade social brasileira profundamente desigual, na qual pessoas negras continuam em condições precárias de vida, nos mais diversos campos. Nesse sentido, torna-se importante visibilizar e nomear tais experiências como experiências racistas em prol do desmantelamento do discurso da democracia racial, pois estas próprias experiências denunciam sua inexistência.

Esta forma de racismo "à brasileira" (MUNANGA, 2014) opera a partir de uma ambiguidade entre, de um lado, um discurso de invisibilização e negação das experiências de racismo que invalida as denúncias feitas do cotidiano de pessoas que vivenciam experiências explícitas ou não, e, de outro lado, naturaliza essas opressões como comuns, banais, "coisas que acontecem com todo mundo". Este aspecto do "não-explícito", vale ressaltar, toca também na dimensão estrutural do racismo ${ }^{15}$. Isso se confirma na reflexão do relato de Michou.

Michou fala de seu profundo incômodo enquanto estrangeira no Brasil, e que embora relate as situações de racismo como aspectos desagradáveis, diz que o maior problema não é esse; para ela, o problema é que as pessoas fazem juízos de valor sobre ela, falam sobre onde ela deveria estar, antes mesmo que ela diga quem ela é ou demonstre suas capacidades. Comenta que sair de seu país para estudar era seu grande sonho, porém não gostaria de seguir sua carreira acadêmica no Brasil. Que os problemas que teve com relação à moradia ou à não integração com sua turma da Graduação fizeram-na se questionar sobre seu próprio caráter, sobre ser ela uma "pessoa dificil" de se relacionar (informação verbal) ${ }^{16}$. Sobre o racismo, acredita que algumas pessoas ficam receosas de falar sobre a questão, pois quem

\footnotetext{
15 Para Antônio Lima Junior e Carolina Cherfem (2016), foi o avanço do debate em torno do racismo institucional que possibilitou visibilizar as desigualdades estruturais do povo negro na sociedade brasileira, contribuindo para a agenda política do movimento negro que culmina com a demanda das ações afirmativas, por exemplo. Uma das perspectivas do racismo estrutural é a de que a modernidade e o capitalismo se erigiram tendo como base a desigualdade racial e buscam mecanismos para se manter assim, principalmente por meio das instituições (ALMEIDA, 2018).

16 Informação fornecida por Michou em entrevista, em Belo Horizonte, em 25 de agosto de 2017.
} 
ouve pode considerar que é "mimimi" (ou seja, pouco importante), e que deveriam voltar para seus paises se encontram que há algo errado por aqui.

Quando Michou relata um incômodo que se agrava no momento em que se questiona sobre ser o problema, sem necessariamente nomeá-lo como racismo, compreendemos que ela está narrando as implicações de ser uma pessoa negra no Brasil. Como afirma a filósofa brasileira Djamila Ribeiro (2018, p. 33), "racismo é um sistema de opressão e, para haver racismo, deve haver relações de poder"; e como tal, aponta Lélia Gonzalez (1982, p. 41), se trata de uma: "construção ideológica cujas práticas se concretizam nos diferentes processos de discriminação racial. Enquanto discurso de exclusão que é, ele tem sido perpetuado e reinterpretado, de acordo com os interesses dos que dele se beneficiam".

Nesse sentido, reiteramos que nomear as situações como as descritas nos relatos como racistas, embora não esteja colocado nesses termos, faz parte de um posicionamento que busca romper com estas invisibilizações e silenciamentos, pois não se pode lutar contra o que, supostamente, não existe (RIBEIRO, 2017).

Outro aspecto interessante que aparece no relato de ambas é a aproximação que elas estabelecem com a comunidade haitiana local, o que possibilita uma importante rede de apoio para estas estudantes. Sobre o tema, as pesquisadoras brasileiras Thula Pires, Vanessa Berner e Julia França apontam que há uma dualidade frequente na situação do imigrante de exclusão que opera quando se "exclui a si mesmo antes de ser excluído e também para não ser excluído" (SAYAD, 1998, p. 269 apud PIRES; BERNER; FRANÇA, 2016, p. 780). Tal visão nos coloca em reflexão também sobre em que medida o comportamento de preferir estar entre os próprios conterrâneos tem a ver também com uma proteção, reconfiguração identitária ou uma defesa diante da exclusão social cotidiana.

Em suas respectivas universidades, Judie e Michou afirmam que foram muito bem recebidas, tanto pelas secretarias de relações internacionais das instituições quanto pelas gestoras responsáveis, que sempre se mostram muito solícitas às demandas que elas possuem, bem como disponíveis a explicitar todas as dúvidas que elas apresentam. Já sobre o cotidiano da universidade: "Sempre foi meu sonho estudar fora, mas eu não estou gostando". Ao perguntar se é da cidade ou da universidade, ela diz: "da universidade eu gosto; o país é 'ok' também, mas a turma e os colegas são os maiores problemas" (informação 
verbal) ${ }^{17}$. No início, as pessoas não a escolhiam para fazer parte dos grupos, e sua competência parecia sempre ser questionada, até ser conquistada.

No primeiro semestre que eu fiz... foi bem... triste pra mim, porque ninguém falava comigo, eu fiquei, tipo, uma pessoa invisivel na sala. Porque acho que todo mundo não... não me conhecia. Parecia uma pessoa invisivel. Mas, nesse segundo semestre, tudo começou com uma... muito bom, muito bom, porque eu falei muito... e como eu fiquei invisivel na sala, eu tinha medo, eu tinha medo de falar, de perguntar... mas agora ficou tudo ótimo para mim porque eu falei, eu perguntei, eu passei minhas ideias, eu tenho tipo um relacionamento mais... apertado [próximo] com os professores e também com meus colegas. [...] está rolando muito, está rolando bem, mais ou menos bem [fazer grupo de trabalho] (Judie) ${ }^{18}$.

Ambas afirmam a respeito de sua invisibilidade na sala de aula, que é causada ou se traduz na crença de que elas são menos capazes que seus demais colegas, seja por serem negras, seja por serem de outro país - local este que é subalternizado possivelmente pela mesma razão. $\bigcirc$ movimento de Judie é o de tornar-se ou fazer-se visível, denunciando, em algum nível, o equívoco preconceituoso de seus colegas de turma. Importante ressaltar aqui que tal situação não pode ser tomada apenas em sua dimensão "superação" (a autonomia no tornar-se visivel); ela revela uma dimensão latente do racismo na vida cotidiana estudantil de pessoas negras ${ }^{19}$.

No que se refere à relação com outros estudantes estrangeiros, embora a comunidade estudantil belo-horizontina não seja acolhedora com as estudantes, eles e elas também não se identificam ou se aproximam de outros estudantes estrangeiros. Existe também uma prática discursiva preconceituosa, no cotidiano, de designar todos os estrangeiros negros e negras como africanos, o que causa inclusive estranhamento entre os e as próprias estudantes, que buscam diferenciar-se entre si. Parece interessante a reflexão de que a questão racial, por si só, não une nem estrangeiros entre si, nem estrangeiros e brasileiros, justamente porque ela incide de maneira distinta a depender da categoria de território e nacionalidade ${ }^{20}$.

\footnotetext{
17 Informação fornecida por Michou em entrevista, em Belo Horizonte, em 25 de agosto de 2018.

18 Informação fornecida por Judie em entrevista, na Belo Horizonte, em 5 de setembro de 2018.

19 Para reflexões mais aprofundadas sobre estudantes negros brasileiros no ensino superior articulando também o debate sobre as ações afirmativas, ver pesquisa de Ricardo Dias de Castro (2017) intitulada Nós queremos reitores negros, saca?: Trajetórias de universitários negros da classe média na UFMG, que apresenta relatos semelhantes acerca das experiências de racismo na universidade.
}

20 Para muitas estudantes de países africanos e haitianas, muitas mulheres que se autodeclaram negras, como a pesquisadora que thes entrevistava - mulher negra de pele clara - em seus países seriam consideradas brancas (ou mulatas). 
Ao partir da identificação enquanto estrangeiro ou estrangeira localizado(a) em um país cujos estereótipos de pobreza e vulnerabilidade social são tão fortemente marcados, tais estudantes ficam sujeitos a um outro tipo de essencialização ou inferiorização.

Ou seja, estão expostos ao racismo por serem negros e negras - a questão fenotípica da negritude é uma característica externa, visivel, e, na sociedade brasileira, coloca as pessoas em uma situação de desigualdade e de opressão; e quando identificam sua origem, passam por um outro tipo de interpelação opressora, dessa vez, do lugar do desconhecimento. No entanto, como já apontamos, o racismo envolve uma relação de poder. Há uma associação com a miséria, pobreza, mas principalmente, com a selvageria, o "primitivismo" social, entre outros estereótipos pejorativos que explicitam a lógica racista que permeia esse suposto desconhecimento, que nada tem de ingênuo. É justamente na resposta a esta interpelação que tais estereótipos podem ser desconstruídos.

Enquanto Michou nunca havia pensado antes no Brasil para estudar, mas sabia que "queria conhecer mais o mundo (e por isso não ficar no Haiti)" (informação verbal)"21, Judie afirma: "Eu escolhi Brasil por que... tem mais oportunidades, e também, é mais fácil pra entrar numa universidade daqui" (informação verbal) ${ }^{22}$. Para ambas, a França aparecia como uma opção mais interessante, mas o acesso ao país, as oportunidades de bolsa e outras questões as fizeram manter o Brasil como escolha. Vale ressaltar também que ambas foram aprovadas em outros processos seletivos: Michou em Cuba e Judie na França e na Rússia.

Ao fazer sua inscrição no PEC-G, Michou colocou como opções de desejo as cidades de Brasilia e São Paulo. No caso de Judie, outros caminhos a levaram para Belo Horizonte e à universidade na qual acabou se inserindo: já tinha um amigo cursando ensino superior na cidade e um primo que havia migrado há algum tempo.

Um levantamento realizado por pesquisadores do Observatório das Migrações Internacionais do Estado de Minas Gerais (OBMinas) e pesquisadores da PUC Minas, a partir das informações públicas declaradas pelos imigrantes do estado à PF, foi disponibilizado no dia 24 de outubro de 2018 no site da instituição. A realidade migratória do estado de Minas Gerais indica uma maioria de residentes na capital do estado, Belo Horizonte, a

21 Informação fornecida por Michou em entrevista, em Belo Horizonte, em 25 de agosto de 2017.

22 Informação fornecida por Judie em entrevista, em Belo Horizonte, em 5 de setembro de 2018. 
maioria de homens, a ocupação indicada é a estudantil e o país que mais traz imigrantes é o Haiti, sendo 3.241 residentes dos quase 21 milhões de mineiros e mineiras.

Ao filtrar os dados com residentes provenientes apenas do Haiti, estas informações se modificam, com exceção da questão de gênero. Com exceção da faixa etária de $\mathrm{O}$ a 14 anos, se mantém a maioria masculina. $\mathrm{Na}$ faixa etária entre 20 a 39 anos, a diferença é de duas vezes mais mulheres que homens; entre 40 a 59 anos, essa diferença é três vezes maior. A redução desta diferença entre mulheres mais jovens pode revelar uma mudança geracional, ao longo do tempo, no perfil da diáspora haitiana (ATLAS..., 2018).

No que se refere à opinião das interlocutoras com relação à cidade, Michou diz que gosta de Belo Horizonte e da cidade, mas confessa que seu sentimento diminuiu um pouco devido aos assaltos que sofreu (dois neste ano de 2018, ambos retornando para casa depois da faculdade, ambos durante o dia. Já Judie afirma: "Gosto. Porque... acho que... agora, eu estou fazendo, eu estou... abrindo a minha mão pra fazer muitas amizades, eu já tenho muitas pessoas, é... mas na verdade eu gosto dos lugares bem calmos. Porque Belo Horizonte é tão grande, tão cheio, motoristas, carros... são muitas pessoas" (informação verbal) ${ }^{23}$.

Apesar de se surpreenderem com algumas questões, ambas têm visto a experiência com a cidade como algo positivo. Vale ressaltar, no contexto local, a importância de instituições como o Coletivo de Mulheres Migrantes Cio da Terra, o Centro Zanmi (Serviço Jesuíta a Migrantes e Refugiados) e a Casa Tina Martins, que têm atendido majoritariamente haitianos e haitianas na capital e região metropolitana. Judie e Michou não frequentavam as instituições, mas já tinham ouvido falar delas. Podemos pensar que a chegada no país por meio do PEC-G coloca também outras relações com a cidade, ou seja, a de circular em espaços universitários e com a comunidade haitiana que está na universidade.

No contexto das estudantes haitianas com as quais tive contato, pude constatar que todos os estudantes haitianos e haitianas da universidade federal ganhavam algum tipo de bolsa, seja do programa, seja da universidade, para se sustentar. $\mathrm{Na}$ universidade privada não foi encontrada essa informação de maneira precisa, mas Judie ainda não tinha sido contemplada com nenhuma das opções de bolsas, e as demais estudantes que ingressaram pelo vestibular brasileiro tinham sua condição como migrante regularizada, o que as permitia trabalhar. Não se poderia afirmar que todos

23 Informação fornecida por Judie em entrevista, em Belo Horizonte, em 3 de setembro de 2018. 
os estudantes haitianos e haitianas que vêm para o Brasil se mantêm apenas com bolsas, pois existem muitas pessoas que são sustentadas pela família, pelo menos no início do processo. Por outro lado, esta questão torna as experiências destas duas estudantes em uma experiência muito particular:

Michou veio para o Brasil com ajuda financeira da familia e agora vive com bolsa. Já teve Bolsa Mérito (que é concedida pelo Itamaraty), mas perdeu porque ela é condicionada ao coeficiente do estudante aferido pelo Rendimento Semestral Global (RSG); ganhou a bolsa Milton Santos no ano passado, que era válida até dezembro; conseguiu uma bolsa da universidade e com ela se manterá até o fim do curso, mas pretendia recorrer à Fundação Universitária Mendes Pimentel (Fump) caso ela não vingasse.

Judie se sustenta com a ajuda da família e dos amigos. Estava iniciando no segundo ano do curso e até o momento não conseguiu nenhuma bolsa [a maioria delas exige ter cursado um ano]. Ela aponta que vive com as ajudas de amigos haitianos no Brasil e quando possivel dos familiares.

Associar tais leituras sobre a diáspora haitiana pela ótica das mulheres e aos relatos do campo, nos possibilitou refletir que as escolhas das redes no local de destino são atravessadas por inúmeros e complexos elementos. $\bigcirc$ que queremos pontuar com isso é que as decisões de "fechar-se" ou "abrir-se" à comunidade externa estão agenciadas por diversos fatores, entendendo também que não se tratam de escolhas estanques, pois não só se abre ou só se fecha; o lugar da diáspora é um lugar de constantes (re)negociações.

Portanto, este aspecto da conformação de redes - dentro da comunidade haitiana ou fora - se apresenta como algo necessário e imprescindivel para uma experiência de potencialidades. São as redes que nutrem e fortalecem a experiência, sendo um tipo de vínculo com a nacionalidade, que não necessariamente se dá no/pelo território. Ou seja, são as redes de apoio criadas nos países de destino e a frequente comunicação com familiares e amigos (que podem ou não estar no Haiti) que são identificadas como uma espécie de fôlego para as inundações frequentes de situações desagradáveis e violentas, entendendo também que mesmo nesse espaço podem haver conflitos.

Uma das potências da universidade como espaço de crescimento está nas projeções de futuro que ela evoca ou fomenta. Dentro da diáspora estudantil, a pergunta sobre o futuro é particularmente importante, pois evoca pensar sobre o que de fato se trata este fenômeno. Em si mesma, ela produz um paradoxo. Em teoria, o futuro é previsto pelo programa através da obrigação de retornar ao país ao fim do curso. Dentro disso, as estudantes costumam 
traçar planos para os próximos passos. $\bigcirc$ paradoxo mora na incerteza destes planos, pois estão sujeitos a acordos acadêmicos, disponibilidade de bolsas, aprovação em um processo seletivo, entre outros aspectos.

Nesse sentido, Michou sempre falou com muita alegria acerca de seu curso e os projetos com os quais teve oportunidade de se engajar desde que chegou ao Brasil. Fala também sobre a vontade de continuar se profissionalizando academicamente, desejo também compartilhado por Judie. Mesmo estando no início da graduação, ela já se projeta para o futuro acadêmico - Mestrado e Doutorado -, ainda que se sinta pressionada às vezes com o volume de informações que o curso acarreta.

\section{Considerações Finais}

Ao longo do texto buscamos analisar as trajetórias em diáspora de universitárias haitianas em Belo Horizonte. Três pontos nodais de reflexão acerca do que escolhemos chamar de insurgências guiaram nosso percurso e argumentos: a diáspora estudantil; a diáspora negra; e os atravessamentos das questões de gênero na diáspora. Concluiremos tais pontos a seguir.

Há uma hipótese equivocada de que nesta cisão entre os migrantes e estudantes migrantes esteja uma questão de classe. Considerando que o PEC-G é um acordo que supõe uma ajuda financeira familiar, estes jovens, que têm a oportunidade de migrar para estudar, supostamente estariam em melhores condições financeiras. No entanto, os dois lados apresentam contestações a essa perspectiva. Existem estudantes, e não somente haitianos e haitianas, que não são custeados pela família como supõe o acordo, conforme apontam as próprias trajetórias de Judie e Michou.

No que concerne à transformação da universidade, sobretudo a universidade pública, entendemos que isso tem se dado justamente pela presença destes e destas estudantes, com demandas completamente diferentes ao espaço, sobre a sua permanência, mas também às formas de produção de conhecimento que também foram historicamente erigidas de forma elitista. Nesse sentido, também a experiência vivida e trazida por estudantes em acordos bilaterais como o PEC-G se colocam como desafiadoras, importantes e potentes no momento atual, colocando ainda outras tantas demandas acerca da globalização e internacionalização, à lógica mercadológica que já dita as regras nas universidades privadas mas tem se aproximado cada vez mais das universidades públicas, entre outros. 
Parece importante ressaltar que, nos casos específicos de Judie e Michou, ainda que a academia seja o palco de muitas das situações racistas às quais estão expostas, é também o lugar onde elas têm tido contato com outras possibilidades de ser e existir enquanto as pessoas que são de maneira muito autônoma, demonstrada inclusive no desejo de poder seguir se qualificando academicamente.

Em segundo lugar, a questão racial em termos de discriminação, preconceito racial e racismo aparece em todos os relatos dos e das interlocutores(as) da pesquisa de Mestrado parcialmente aqui apresentada. Mulheres e homens relatam episódios distintos, com destaque para a percepção de que as pessoas "mudam de faixa na rua quando elas passam", ou "seguram mais forte a bolsa", que aparece em todos os relatos.

Na perspectiva da antinegritude proposta por João Vargas (2017), um dos efeitos póstumos da escravização é que a violência gratuita que se destina à pessoa negra não depende de algo que você faz ou deixa de fazer, e sim pelo que se é, em uma estrutura de posicionalidade que gera valor social que varia a depender do quanto você está perto ou longe da negritude. Para o nosso caso, significa dizer, como eles e elas apontam, que ambos serão lidos como potenciais agressores por simplesmente caminhar na rua, ou seja, o racismo opera pela nossa existência.

Ainda que as estudantes tentem se identificar como não-brasileiras, possivelmente numa alternativa de deixarem de ser alvo do racismo na sociedade brasileira, existem outras evidências que apontam que, ainda assim, o tratamento continua sendo diferente e hierarquizado de maneira inferior. E como dissemos, não é novidade a denúncia sobre a desigualdade social no Haiti ser construída e mantida por interesses políticos dos mesmos atores históricos ao longo do tempo. Não é novidade, também, que a diáspora seja um dos grandes sintomas que denuncia esse mal-estar da sociedade haitiana.

A novidade aqui é, talvez, fazer dialogarem estes sistemas de opressão nos dois locais, Brasil e Haiti, conectados com outros países, balizados pela raça. Ou seja, há um projeto colonizador que não se acaba, e dentro dele moram muitas faces de um mesmo genocídio da população negra, esteja ela em diáspora dentro ou fora do território que hoje ocupa.

A terceira e última reflexão é que, ao pensar sobre a diáspora articulando a perspectiva de gênero por meio da experiência de Judie e Michou, as primeiras de suas familias a saírem de casa para estudar, que acabam por se tornar figuras de referência para que os demais - inclusive sendo o ponto 
(e o porto) para que outros membros da família possam também se tornar diáspora -, possamos ver possibilidades (e não só uma utopia). Elas inventam e reinventam formas de manter esta trajetória possivel, considerando todos os atravessamentos externos, como os da origem (de virem de familias em situação de vulnerabilidade social e financeira e/ou familias que não acolhem imediatamente seus projetos de formação profissional/acadêmica), como os problemas locais - serem recebidas como corpos indesejáveis, serem atravessadas pela condição da mulher negra em nosso país, entre outros.

Tentando afastar-se de uma perspectiva essencialista, evocar a experiência destas mulheres é chamar atenção para o que se incide nas diversas articulações possiveis de identidades sociais e o que se faz com elas. Como denuncia Simmonds (1997 apud Mirza, 2015, p. 2, tradução nossa): "O mundo que eu habito como uma acadêmica é um mundo branco... nesse mundo branco, eu sou um peixe de água doce que nada em alto mar. E sinto o peso da água no meu corpo". Ainda que não reivindiquem aqui uma organização política, estas mulheres inscrevem, com o corpo, trajetórias de luta e resistência.

Por fim, a diáspora estudantil de mulheres haitianas não pode ser explicada pura e simplesmente como uma insurgência. A reflexão que desejamos postular aqui é a de que o deslocamento territorial de Judie e Michou aponta para uma política de insurgência do status quo.

\section{Referências}

ALMEIDA, S. O que é racismo estrutural? Belo Horizonte: Letramento, 2018.

AMARAL, J. Atravessando o Atlântico: o programa estudante convênio de graduação e a cooperação educacional brasileira. 2013. Dissertação (Mestrado em Desenvolvimento, Sociedade e Cooperação Internacional) - Universidade de Brasilia, Brasilia, 2013.

ANZALDÚA, G. La conciencia de la mestiza: rumo a uma nova consciência. Estudos Feministas, Florianópolis, v. 13, n. 3, p. 704-719, 2005.

APPADURAI, A. Soberania sem territorialidade. Notas para uma geografia pós-nacional. Novos Estudos Cebrap, São Paulo, n. 49, p. 33-46, 1997.

ATLAS digital da migração internacional em Minas Gerais. PUC Minas, Belo Horizonte, 2018. Disponível em: https://bit.ly/3hW7qlb. Acesso em: 11 out. 2019. 
BRASIL. Lei $n^{0} \mathbf{1 . 8 0 2}$, de 5 de janeiro de 1953. Define os crimes contra - Estado e a Ordem Política Social, e dá outras providências. Brasilia, DF: Presidência da República, 1953.

BRAUM, P.; DALMASO, F.; NEIBURG, F. Gender issues: relations between men and women in the low-income districts of Port-au-Prince. Rio de Janeiro: UFRJ, 2014. Disponivel em: https://bit.ly/2B9t6JX. Acesso em: 25 jun. 2020.

CASTRO, R. Nós queremos reitores negros, saca?: trajetórias de universitários negros de classe média na UFMG. 2017. Dissertação (Mestrado em Psicologia) Universidade Federal de Minas Gerais, Belo Horizonte, 2017.

CHAUÍ, M. A universidade pública sob nova perspectiva. Revista Brasileira de Educação, Rio de Janeiro, n. 24, p. 5-15, 2003.

CHAVES JÚNIOR, E. Um olhar sobre o Haiti: refúgio e migração como parte da história. Brasilia: LGE, 2008.

CIVIL, J. Dobras do tempo: a comunicação entre passado e presente a partir de experiências de imigração, racismo e desigualdades de gênero em relatos orais de haitianas em Belo Horizonte. 2018. Trabalho de Conclusão de Curso (Graduação em Comunicação Social) - Universidade Federal de Minas Gerais, Belo Horizonte, 2018.

CLIFFORD, J. Diásporas. In: GOLUBOV, N. Diáspora: reflexiones teóricas. Cidade do México: Universidad Nacional Autónoma de México, 2011. p. 85-126.

ELEIÇÕES no Haiti: 18 candidatos, seis favoritos. G1, São Paulo, 25 de novembro de 2010, 11:02. Disponivel em: https://glo.bo/304L88B. Acesso em: 13 jul. 2020.

FERNANDES, D.; FARIA, A. O visto humanitário como resposta ao pedido de refúgio dos haitianos. Revista Brasileira de Estudos de População, São Paulo, v. 34, n. 1, p. 145-161, 2017.

FERREIRA, R. Estudantes estrangeiros no Brasil: migrações, informação e produção de diferença. 2017. Tese (Doutorado em Ciência da Informação) Universidade Federal do Rio de Janeiro, Rio de Janeiro, 2017. 
FIGUEROA, A.; HURTADO, K. Feminismo afrodiaspórico: una agenda emergente del feminismo negro en Colombia. Universitas Humanística, Bogotá, n. 78, p. 109-134, 2014.

FRANCISCO, C. R. Trajetórias em diáspora: a experiência de universitárias haitianas de Belo Horizonte. 2019. Dissertação (Mestrado em Psicologia) Universidade Federal de Minas Gerais, Belo Horizonte, 2019.

FREITAS, D. Slam resistência: poesia, cidadania e insurgência. Estudos de Literatura Brasileira Contemporânea, Brasilia, DF, n. 59, p. 1-15, 2020.

GILROY, P. O Atlântico negro: modernidade e dupla consciência. Rio de Janeiro: Universidade Candido Mendes, 2001.

GOMES, M. Os impactos subjetivos dos fluxos migratórios: os haitianos em Florianópolis (SC). Psicologia \& Sociedade, Belo Horizonte, v. 29, p. 1-11, 2017.

GONZALEZ, L. A mulher negra na sociedade brasileira. In: LUZ, M. T. O lugar da mulher: estudos sobre a condição feminina na sociedade atual. Rio de Janeiro: Edições Graal, 1982. p. 87-106.

GORDON, E. The Austin school manifesto: an approach to the black or African diaspora. Cultural Dynamics, Thousand Oaks, v. 19, n. 1, p. 87-106, 2006.

GORDON, E.; ANDERSON, M. The African diaspora: toward an ethnography of diasporic identification. Journal of American Folklore, Champaign, v. 112, n. 445, p. 282-296, 1999.

GRONDIN, M. Haiti: cultura, poder e desenvolvimento. São Paulo: Brasiliense, 1985. (Coleção Tudo é História).

HALL, S. Pensar en la diáspora: en casa, desde el extranjero. In: GOLUBOV, N. Diáspora: reflexiones teóricas. Cidade do México: Universidad Nacional Autónoma de México, 2011. p. 127-148.

HANDERSON, J. Diáspora: sentidos sociais e mobilidades haitianas. Horizontes Antropológicos, Porto Alegre, ano 21, n. 43, p. 51-78, 2015.

HANDERSON, J. A historicidade da (e)migração internacional haitiana: o Brasil como novo espaço migratório. Periplos, Brasilia, DF, v. 1, n. 1, p. 7-26, 2017. 
HANDERSON, J.; JOSEPH, R. M. As relações de gênero, de classe e de raça: mulheres migrantes haitianas na França e no Brasil. Revista de Estudos e Pesquisas sobre as Américas, Brasilia, DF, v. 9, n. 2, p. 1-33, 2015.

HUR, D.; LACERDA JÚNIOR, F. Ditadura e insurgência na América Latina: psicologia da libertação e resistência armada. Psicologia: Ciência e Profissão, Brasilia, DF, n. 37, p. 28-43, 2017.

LACAZ, A. S. Desafios da militância na esquerda: artefatos para a insurgência. Arquivos Brasileiros de Psicologia, Rio de Janeiro, v. 70, n. spe., p. 59-74, 2018.

LIMA JUNIOR, A. T.; CHERFEM, C. O. Igualdade racial. In: INSTITUO BRASILEIRO DE PESQUISAS ECONÔMICAS E APLICADAS. Políticas sociais: acompanhamento e análise. Brasilia, DF: Ipea, 2016.

MAGALHÃES, L. F. A. O Haiti é aqui: sub imperialismo brasileiro e imigrantes haitianos em Santa Catarina, SC. Revista Brasileira de Estudos Latino-Americanos, Florianópolis, v. 5, n. 1, p. 13-43, 2015.

MAGALHÃES, L. F. A. A imigração haitiana em Santa Catarina: perfil sociodemográfico do fluxo, contradições da inserção laboral e dependência de remessas no Haiti. 2017. Tese (Doutorado em Demografia) - Universidade Estadual de Campinas, Campinas, 2017.

MATUELLA, I. Conflitos armados e a agenda internacional: a questão da mulher. Estudos Feministas, Florianópolis, v. 25, n. 3, p. 1277-1295, 2017.

MAYORGA, C. Cruzando fronteiras: prostituição e imigração. Cadernos Pagu, Campinas, v. 37, p. 323-355, 2011.

MAYORGA, C.; NASCIMENTO, R. F. Dinâmicas da transformação social: reflexões sobre a pesquisa-ação em contextos comunitários. In: MAYORGA, C.; PEREIRA, M.; RASERA, E. (orgs.). Psicologia social: sobre desigualdades e enfrentamentos. Curitiba: Juruá, 2009. p. 162-179.

MIRZA, H. S. Decolonising higher education: black feminism and the intersectionality of race and gender. Journal of Feminist Scholarship, Darthmouth, v. 7, n. 8, p. 1-12, 2015. 
MUNANGA, K. Prefácio. In: CARONE, I.; BENTO, M. A. (orgs.). Psicologia social do racismo: estudos sobre branquitude e branqueamento no Brasil. 6. ed. Petrópolis: Vozes, 2014. p. 7-9.

PATRICK, I. Aquilo que resta de nós: um pedido de socorro de haitianas estupradas por soldados da ONU. Belo Horizonte: Páginas, 2017.

PERES, R. Imigração e gênero mulheres haitianas. In: BAENINGER, R. et al. (orgs.). Imigração Haitiana no Brasil. Jundiaí: Paco, 2017. p. 639-653.

PIRES, T. R.; BERNER, V. O. B.; FRANÇA, J. M. Os estudantes africanos no brasil na perspectiva da teoria crítica dos direitos humanos. Quaestio luris, Rio de Janeiro, v. 9, n. 2, p. 757-787, 2016.

\section{QUEIROZ, M. V. L. Constitucionalismo Brasileiro e o Atlântico Negro:} a experiência constituinte de 1823 diante da Revolução Haitiana. 2017. Dissertação (Mestrado em Direito) - Universidade Federal de Brasilia, Brasilia, DF, 2017.

REGINENSI, C.; MENEZES, M. Processos insurgentes de cidadania: as múltiplas interpretações da relação entre materialidade dos espaços públicos e as práticas sociais. In: CONGRESSO LUSO-AFRO-BRASILEIRO DE CIÊNCIAS, 10., 2009, Braga. Anais [...]. Braga: Universidade do Minho, 2009. p. 847-858.

REIS, M. L. M. R. A Diáspora e o movimento social das mulheres afrodescendentes das Américas. In: CONGRESSO LUSO AFRO BRASILEIRO DE CIÊNCIAS SOCIAIS, 11., 2011, Salvador. Anais [...]. Salvador: Universidade Federal da Bahia, 2011.

RIBEIRO, D. Seja racista e ganhe a fama e empatia. In: RIBEIRO, D. Quem tem medo do feminismo negro? São Paulo: Companhia das Letras, 2018. p. 31-33.

ROMAGNOLI, R. C. O conceito de implicação e a pesquisa-intervenção institucionalista. Psicologia \& Sociedade, Belo Horizonte, v. 26, n. 1, p. 44-52, 2014.

SANTOS, S. B. Feminismo negro diaspórico. Gênero, Niteröi, v. 9, n. 1, p. 11-26, 2000. 
SEGUY, F. A catástrofe de janeiro de 2010: a "internacional comunitária" e a recolonização do Haiti. 2014. Tese (Doutorado em Sociologia) - Universidade Estadual de Campinas, Campinas, 2014.

SEITENFUS, R. Reconstruir Haití: entre la esperanza y el tridente imperial. Santo Domingo: Fundación Juan Bosch, 2016.

SILVA, M. M. Insurgência e conservadorismo: considerações sobre o paradoxo da cidadania no Brasil. Em Pauta, Rio de Janeiro, n. 39, v. 15, p. 70-84, 2017. SIMÕES, A.; HALLAK NETO, J.; CAVALCANTI, L.; OLIVEIRA, T.; MACÊDO, M. Relatório RAIS: a inserção socioeconômica dos imigrantes no mercado de trabalho formal. Brasilia, DF: OBMigra, 2019.

SPINK, P. K. Pesquisa de campo em psicologia social: uma perspectiva pósconstrucionista. Psicologia \& Sociedade, Florianópolis, v. 15, n. 2, p. 18-42, 2003.

VARGAS, J. Por uma mudança de paradigma: antinegritude e antagonismo estrutural. Revista de Ciências Sociais, Fortaleza, v. 48, n. 2, p. 83-105, 2017.

Recebido em março de 2020.

Aprovado em junho de 2020. 